\title{
Brief Background
}

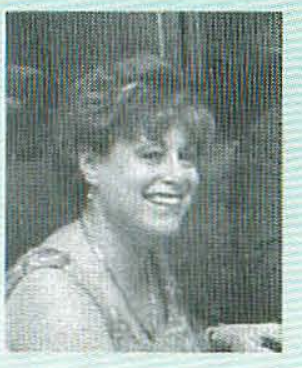

Jil S. Oberstein, MA OTR/

received a B.S. degree in

Occupational Therapy from New

York University and an M.A. degree in Educational Leadership from the University of Central Florida in Orlando, Florida. She

also earned a certificate in Assistive Technology Applications from California State University at Northridge. She has more than two and a half decades of experience as an occupational therapist in a variety of health care and educational settings in Arizona, Florida, and New York, and has worked extensively with persons having a wide range of disabilities across the age span. As a specialist in assistive technology, Ms. Oberstein is the director of the Arizona Technology Access Program (Arizona's assistive technology Act Project) at Northern Arizona University. The program's statewide mission is to help people with disabilities understand and gain acess to assistive technology. Ms. Oberstein has presented at numerous international, national, regional, and state conference on assistive technology related topics. She is also an adjunct instructor in the Occupational Therapy Program at the Arizona School of Health Sciences.

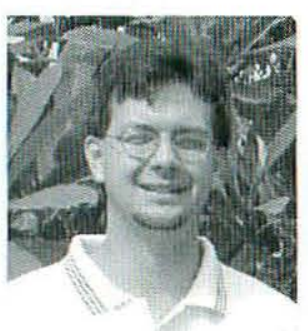

Michael 'Mike' Terlaje is a native of "Yona Rules", Guam and a graduate of Marquette University in Wisconsin where he earned a Bachelor of Science degree in Civil Engineering. His background in this field has served as an ideal springboard in dealing with issues related to accessibility, especially as mandated in the Americans with Disabilities Act. His professional interest in accessibility is strengthened by a practical need to assist one of his older brothers who is a wheelchair user and consumer of a wide range of assistive technology. In addition to the background, he has worked as a Math teacher in a public middle school, and experience that has provided an excellent foundation for his skills as a trainer. He currently works as the A.T. Specialist at the Guam System for Assistive Technology, a project under the University of Guam, Center for Excellence in Developmental Disabilities, Research, and Services, better known as Guam CEDDERS.

Gregory 'Gregg' Borja worked in the Public School System in the fields of Physical Education, Reading, and Technology. In an effort to broaden his experience, he joined the Northern Marianas Protection and Advocacy Systems, Inc. (NMPASI). Greg is currently a Project Specialist, serving as an Advocate for individuals with disabilities on the islands of Tinian and Rota, as well as implementing outreach efforts to create community awareness on the issues surrounding disabilities.

Raymond 'Ray' Palacios worked in the Public School System for 9 years as a Classroom Teacher before moving to the Northern Marianas Protection and Advocacy Systems, Inc. (NMPASI) He enjoys participating in community and local sporting events. Ray is currently a Client Advocate, serving the islands of Saipan, which he finds exciting and challenging, as he represents and defends the rights of individuals with disabilities.

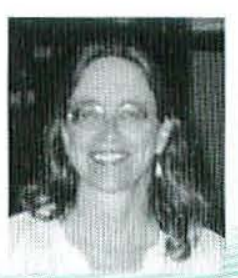

Anita Nilmodian, M.S.W. is a Certified Sign Language Interpreter and presently a Sign Language Instructor with over 30 years of experience working with Deaf, Hard of Hearing, and Deaf-Blind people. She is currently teaching at Northern Marianas College in Saipan after thirteen years of living and working in Washington D.C. area including Gallaudet University. Prior to that, she lived and worked in Southern California, including California State University, Northridge in the West Coast's largest college program serving Deaf and Hard of Hearing students. 


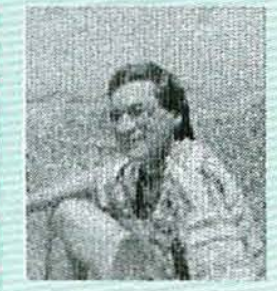

Dr. Joey Wallace is a Policy Analyst and Funding Specialist with both the Virginia Institute on Developmental Disabilities and the Virginia Assistive Technology System. He has over 25 years of experience supporting individuals with disabilities and their families. Joey has had a variety of work experiences including case management, residential services, advocacy, policy development and teaching. He has a Masters in Rehabilitation Counseling from the University of Maine and a Ph.D. from Virginia Commonwealth University. He is the author of multiple journal articles, textbook chapters, and topic papers on a variety of disability-related areas. Dr. Wallace is an individual dedicated to the provision of systems change and personal advocacy for all persons with disabilities. He has committed himself to the creation and development of assistive technology loan programs across the country.

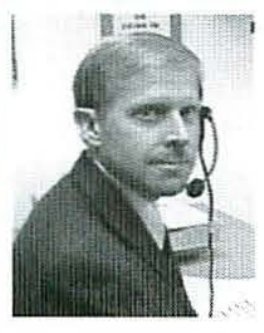

Eric Morrison, M.A., is Lead Faculty for Disabled Student Resources at Pima Community College in Tucson, Arizona, the 5th largest multi-campus community college system in the United States. Mr. Morrison established Assistive Technology (AT) capacity at the College for labs, libraries, and classrooms, and is passionate about the the creative application of these powerful electronic prosthetic devices and technological agents. He has published on special technologies in "Careers and the Disabled Magazine." Currently, Mr. Morrison is the President of the Arizona Postsecondary Access Coalition, a statewide chapter of AHEAD that advocates on behalf of persons with disabilities.

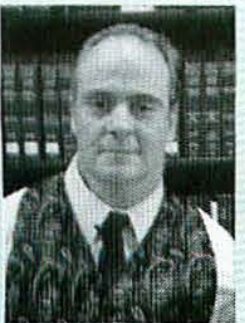

Brian Shaughnessy was born and raised in the cold State of Minnesota. In 1983 he acquired a disability and in 1985 he fled for warmer climates. He finished a Bachelor's Degree in English and theater and and relocated to Hawaii where he earned and MA in theater with an emphasis in directing. He then began to divide this time between Minnesota and Hawaii. In Minnesota he founded Open Door Theatre, a theater group by for and about persons with disabilities. Weary of an the annual migration between Hawaii and Minnesota he opted for a simpler life. He enrolled in law school. Brian graduated and married his wife Amy in 1999 and has been a practicing attorney, public speaker, assistive technology consumer/referral source and writer since. His book, The Squeaky Wheel -- an Unauthorized Autobiography will be published this spring. Brian's greatest role is as the father of one year old Amadeus Yun Chi Shaughnessy.

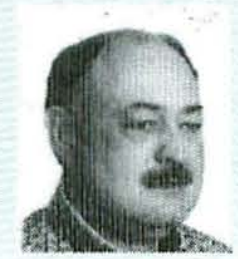

Jerry McVicar received a B.A. in Special Education from Western Washington University, Washington State. He also earned a Certificate in Assistive Technology Application from California State University, Northridge. He taught computer skills and computer maintenance at Marianas Hgh School, Saipan, CNMI. He is currently the AT Specialist of the CNMI Public School System Special Education Program.

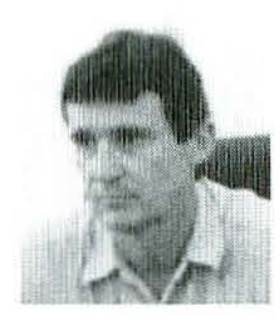

Mike Newman is currently the Manager of the US Social Security on Saipan. He has worked for Social Security on Saipan since 1979. He has nearly 30 years of service with the US Federal Government. He was born and raised in California and have a Bachelor's degree from the University of California at Santa Cruz.

Ms. Dolores Moore is currently the Manager of the Government Health and Life Insurance of the Northern Mariana Islands, Retirement Fund. 


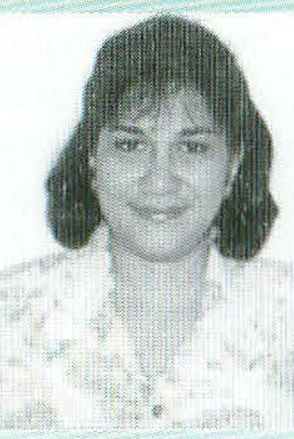

Celia B. Lamkin, M.D. received her Bachelor of Science in Biological Sciences from the State University of the Philippines, Manila, Philippines; her Doctor of Medicine from De La Salle University College of Medicine, Philippines; her postgraduate medical training from the University of the Philipines-Philippine General Hospital in Manila and Postgraduate Course in Occupational Health and Safety from Institute of Public Health-University of the Philippines. As a registered Physician in the Philippines, aside from her private practice, she worked as a Company Physician of garment factories, composing of 4,000 employees, drug manufacturer, medical examiner for insurance company. She worked as a medical consultant of numerous medical clinics, and a Visiting Physician of Medical Center Manila. Dr. Lamkin also worked as an HIV/AIDS Specialist of the Pubic School System. She has done a lot of training and workshops on HIV/AIDS Prevention for administrators, teachers and from K-12 students in elementary and secondary public schools and private schools in the CNMI. She attended numerous training and received numerous certificates concerning HIV Prevention. As a certified HIV Instructor volunteer of the American Red Cross, she conducted a lot of HIV Prevention workshops for the students, parents, civic organizations and the community. Presently, she is working as an Assistive Technology Project Coordinator of the CNMI Council on Developmental Disabilities, Assistive Technology Project for more than 5 years. She receives a lot of training and courses in Assistive Technology. She conducted and coordinated a lot of workshops, training and demonstration of Assistive Technology to teachers, students, parents of children with disabilities, individuals with disabilities, service providers, employers, private and public agencies. She is a member of the American Medical Association and American Diabetes Association.

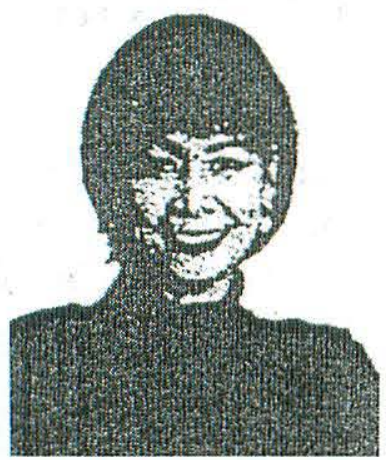

Gia Ramos is a Director with TRI Enterprises, lnc., dba: Healthcare Specialties which is an established Home Medical Equipment (HME) company in Guam since 1992 and subsequently an additional branch in the CNMI since 1996, Mrs. Ramos has been a Registered Nurse for over 20 years with varied experiences in the health care field ranging from ac-ute care/hospital facility, skilled nursing facility, convalescent care/long tenn carc -facility, managed care/HMO, IPO, case management, utilization management, quality/risk management, disease management, clinical staff training, home medical equipment technical certification and home health care management. 